\title{
Optimality-Based Diazotrophy in Different Climate Settings and the Implication to the Marine Nitrogen \\ Cycle
}

\author{
CHIA-TE CHIEN AND MARKUS PAHLOW
}

GEOMAR

Presenting Author: cchien@geomar.de

$\mathrm{N}_{2}$ fixation is the most important nitrogen source to the ocean. Most of the current ecosystem models diagnose autotrophic $\mathrm{N}_{2}$ fixation from the availability of dissolved nutrients, so that it only occurs when the ratio of phosphate-to-nitrate concentrations exceeds the Redfield ratio of $1: 16$, i.e., positive $\mathrm{P}^{*}$. Because water column denitrification lowers $\mathrm{N}: \mathrm{P}$ and thus increases $\mathrm{P} *$ in surface waters via upwelling, the $\mathrm{P}^{*}$ method predicts that $\mathrm{N}_{2}$ fixation is spatially tightly coupled to water column denitrification. However, observed $\mathrm{N}_{2}$ fixation occurs mostly in the oligotrophic subtropical gyres, far away from OMZs and coastal areas, where most water column and benthic denitrification occurs. Thus, our understanding of the mechanisms shaping the spatiotemporal coupling between $\mathrm{N}_{2}$ fixation and denitrification appears to be incomplete. This is especially critical for modelling $\mathrm{N}_{2}$ fixation in different climate settings, such as the last glacial maximum (LGM). The recent development of an Optimality-Based, Non-Redfield PlanktonEcosystem Model (OPEM) offers a new approach for marine ecosystem modelling. In the OPEM, diazotrophs strive mostly in the oligotrophic subtropical gyres, due to their ability to allocate more cellular resources for phosphate uptake, together with topdown control from zooplankton grazing. We will present the distributions of $\mathrm{N}_{2}$ fixation in the OPEM under pre-industrial and LGM conditions, as well as implications to the marine nitrogen cycle. 